\title{
Movimiento ciudadano en el Aljarafe. Por un futuro con pasado
}


El movimiento ciudadano en defensa del patrimonio histórico y el paisaje del Aljarafe ${ }^{\mathbf{1}}$ (comarca de la provincia de Sevilla) intensifica su actividad desde 2006 en la misma proporción en que las amenazas procedentes del urbanismo especulativo se hacen patentes y toman forma en los distintos planes de ordenación de cada municipio. Toda una manera de entender los monumentos como "obstáculos" al desarrollo urbanístico, entra en colisión con los intereses de personas y colectivos que los consideramos elementos esenciales de nuestra identidad y que tienen una incidencia directa en nuestra calidad de vida. De forma natural, espontánea, nos encontramos un grupo numeroso de personas preocupadas por las mismas cuestiones; unos ya pertenecían a asociaciones culturales locales o comarcales², otros lo hacían de forma particular. En cualquier caso, los elementos comunes eran lo suficientemente sólidos como para crear un espacio de colaboración común.

En cada pueblo, fuese cual fuese el partido político gobernante, se repetía el mismo modelo de actuación: desinterés por los bienes culturales, inexistencia de prácticas reales de participación ciudadana y, por otra parte, expectativas de expansión urbanística a un ritmo vertiginoso. Estos elementos nos sitúan en una posición de beligerancia en el escenario del ladrillo, donde están presentes tanto las promotoras, que desean realizar sus proyectos de construcción, como las administraciones locales, habituadas a comerciar con el suelo para lograr su financiación, como la administración autonómica, en la medida en que no ejerce plenamente sus competencias -en este caso, tanto las de ordenación del territorio y tutela urbanística, como las de protección del patrimonio histórico-

Uno de los casos que más preocupados y ocupados nos sigue manteniendo es la situación de riesgo en que se encuentra el yacimiento prehistórico de Valencina de la Concepción y Castilleja de Guzmán. Se trata de un poblado y una necrópolis de la Edad del Cobre con más de
40 dólmenes, que nos revelan la importancia de esta comunidad humana en el Bajo Guadalquivir hace 4000 años. El origen del citado riesgo está, paradójicamente, en la figura elegida por la Consejería de Cultura para formular su declaración como bien de interés cultural ${ }^{3}$ : en vez de abordar de forma integral la protección del yacimiento completo, se eligen exclusivamente los elementos más monumentales, los cinco dólmenes de mayores dimensiones, y además los entornos que se delimitan para cada uno de ellos son extremadamente exiguos. Ésta no es una aseveración arbitraria. Las presiones urbanísticas dejaron su elocuente impronta en el expediente de declaración del Bien de Interés Cultural: se redujo el perímetro protegido del dolmen de Montelirio haciéndolo coincidir, no casualmente, con el proyecto de urbanización que simultáneamente se estaba tramitando. La miopía en la actuación, tanto de los responsables políticos como de los técnicos que instruyeron el expediente en la Delegación Provincial de Cultura de Sevilla, dejaba subliminalmente al resto del yacimiento calcolítico y al paisaje en una situación vulnerable. No quedaba dotado de la protección necesaria para frenar las graves amenazas que llegarían posteriormente, ligadas a proyectos urbanísticos y de transportes. Desde entonces, el dolmen de Montelirio se convirtió en símbolo de la resistencia ciudadana contra la voracidad urbanística, de la lucha de la gente por amor a su tierra.

La valoración del patrimonio megalítico por nuestro movimiento ciudadano tiene una fuerte componente sentimental. Apreciamos el lugar donde vivimos, es nuestro territorio, en el que los espacios, los hitos visuales, las experiencias ligadas a ellos tienen un sitio en nuestra alma, en nuestro patrimonio vivido. El poblado calcolítico ocupó un espacio que ahora está repartido entre dos términos municipales, pero los vecinos de ambos pueblos creemos que sigue siendo "uno" y que ocupa todo lo que ocupó hace 4000 años. Si los vecinos de los dos pueblos nos entendemos, nuestros gobernantes tienen la responsabilidad de 


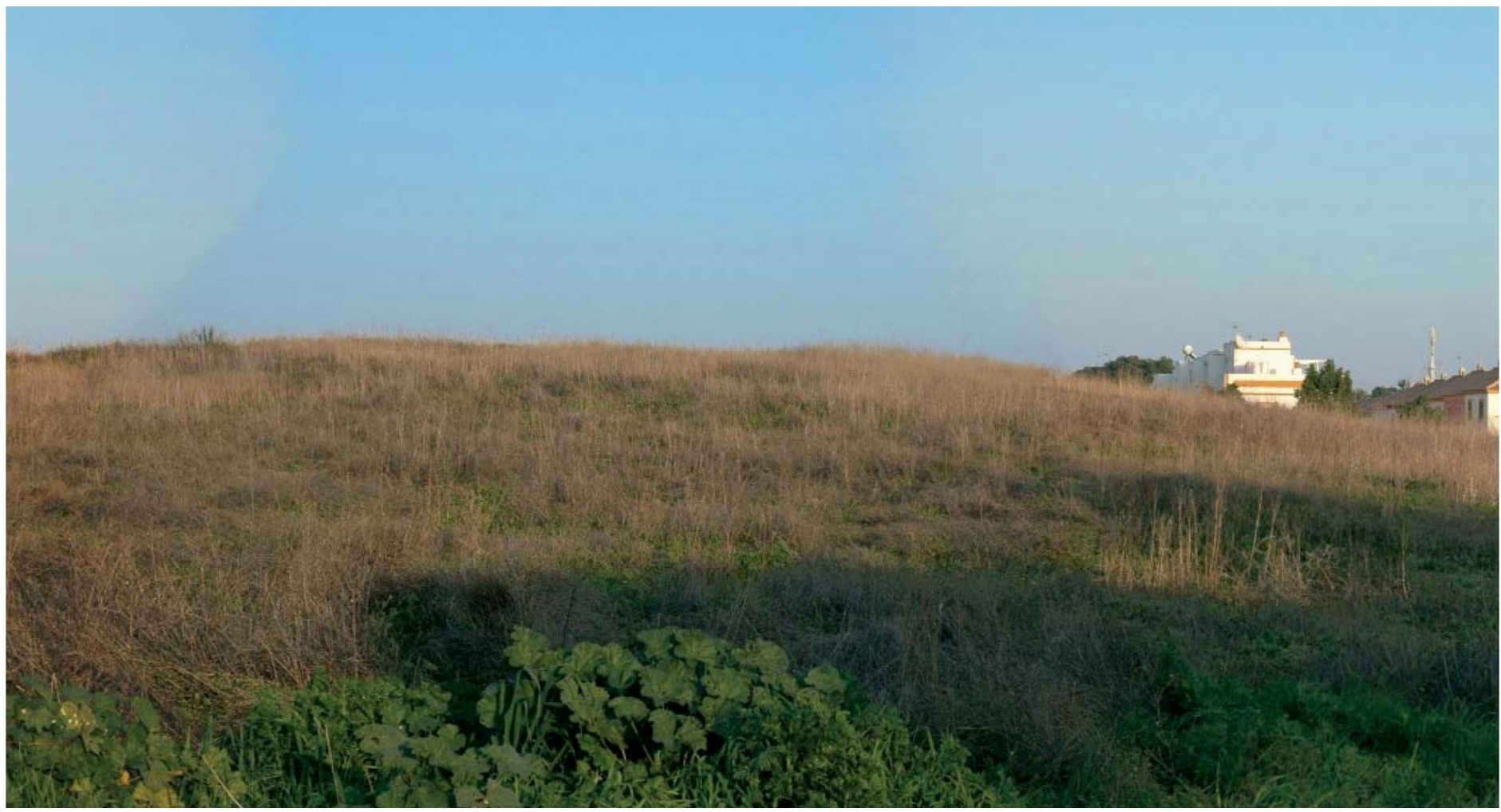

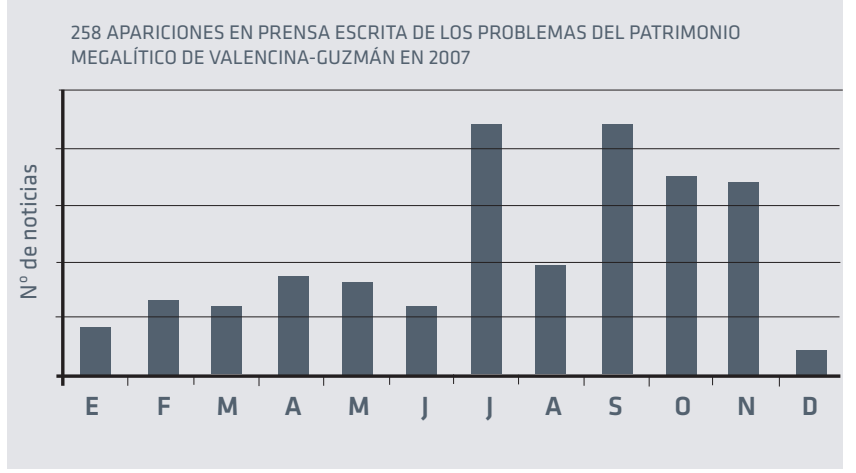

entenderse también y rendirse a la evidencia. A los profesionales, por otra parte, les pedimos que esta visión integral de una zona arqueológica, tan prolijamente presente en la literatura científica, la lleven a la práctica en casos concretos como el de Valencina de la Concepción y Castilleja de Guzmán. Aún se está a tiempo de revisar la figura y el ámbito de protección idóneos.

En nuestro ánimo de colaboración con las administraciones implicadas, elaboramos en el año 2006 una Propuesta de parque arqueológico paisajístico del Aljarafe Norte ${ }^{4}$, que presentamos a las Consejerías de
Cultura, Obras Públicas y Transportes, Medio Ambiente, a la Diputación Provincial de Sevilla y a los Ayuntamientos de Valencina de la Concepción y Castilleja de Guzmán. El objetivo del documento era manifestar la necesidad del adecuado tratamiento para un territorio histórico con importantes valores patrimoniales y paisajísticos y que sufre serias amenazas de fragmentación y devaluación. Los destinatarios recibieron el documento sin más comentario. Un año más tarde, la prensa se hacía eco de la favorable acogida que desde la Consejería de Cultura había tenido una propuesta similar presentada por la Fundación Itálica de Estudios Clásicos para la creación de un Parque cultural del Aljarafe, que incluía tres áreas: Itálica, el poblado y necrópolis de Valencina de la Concepción y Castilleja de Guzmán y el Carambolo.

Nuestra iniciativa surgió como contrapunto al proyecto de una nueva carretera que planificaba la Consejería de Obras Públicas y Transportes, cuyo trazado atravesaba dramáticamente la necrópolis, circunstancia por la que los medios de comunicación acabaron denominándola "la carretera de los dólmenes". La movilización ciudadana fue intensa y unánime: alegaciones al estudio informativo, manifestaciones, marchas, ruedas de prensa... que culminaron en el más satisfactorio ejemplo de participación ciudadana de nuestra trayectoria. En una reunión con varios directores generales, el Delegado Provincial y la mismísima Consejera de Obras Pú- 


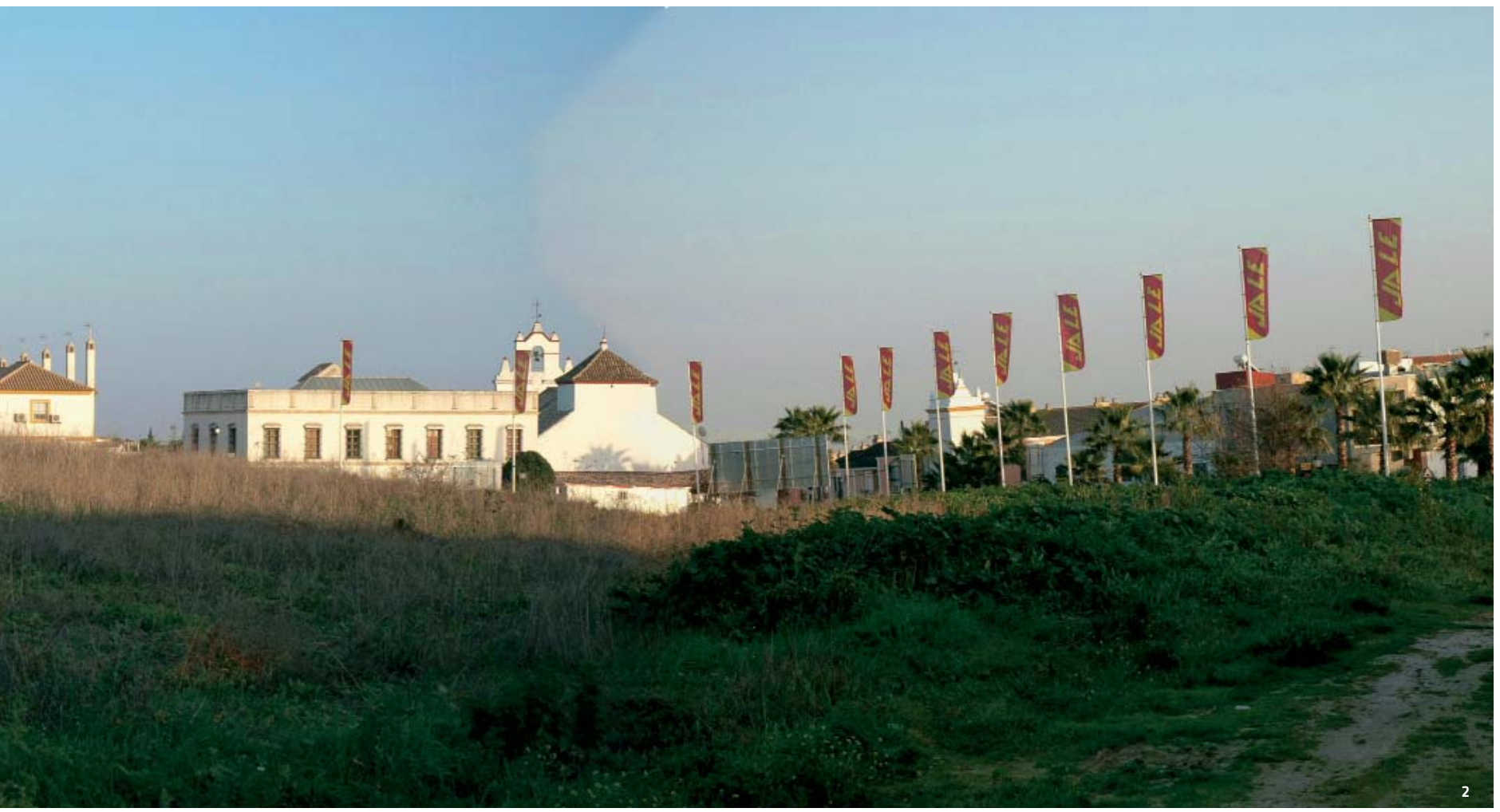

blicas y Transportes se nos comunicaba que tras analizar las circunstancias, consideraban que nuestra alternativa para el trazado de la carretera era la opción más razonable y económica para solucionar el problema del transporte en la zona. Para nosotros no fue sólo un gesto, sino la constatación de que los ciudadanos podemos y debemos involucrarnos en las decisiones que nos afectan a diario con un sentido democrático que supera con mucho la práctica esporádica del voto.

No obstante, pasados dos años el interés por construir la "carretera de los dólmenes" sigue estando vigente y vuelve a amenazarnos en 2008 a través del nuevo anteproyecto de carretera que actualmente está en información pública. Por segunda vez procedemos de igual manera: información a los ciudadanos, alegaciones, divulgación en los medios de comunicación...

Realmente la situación actual nos mantiene extremadamente en alerta. Percibimos frecuentemente la posición indiferente de los responsables de la Consejería de Cultura ante las agresiones al patrimonio, la actitud flexible de sus técnicos que tienen que informar los planes de ordenación del territorio, de infraestructuras y urbanísticos y la primacía de intereses privados en la política urbanística local, llegándose a poner en el mercado inmobiliario suelos que contienen y representan nuestra cultura y nuestro pasado.
Nuestra esperanza está en un cambio de actitud de las personas que gobiernan la Consejería de Cultura, en un nuevo escenario en el que el diálogo sea posible y se tengan en cuenta las razones para la creación del Parque arqueológico paisajístico del Aljarafe Norte. Pondremos todo nuestro interés y trabajo para que la integración sostenible del patrimonio megalítico del Aljarafe en la vida de los ciudadanos llegue a ser una realidad.

\section{Notas}

1 Para más información: forestierdeguzman@gmail.com

2 Asociación cultural grupo arqueológico "Mataherrera", Asociación de amigos del patrimonio arqueológico de Valencina "Los dólmenes", Plataforma ciudadana "Forestier" de Castilleja de Guzmán, Plataforma Aljarafe habitable, Asociación para la defensa del territorio del Aljarafe (ADTA), Asociación "Ber Baso", Ecologistas en acción, Ciudadanos de Espartinas, Guzmán habitable, Plataforma ciudadana Valencina habitable.

3 Orden de 21 de enero de 2003, por la que se resuelve inscribir, con carácter específico en el Catálogo General del Patrimonio Histórico Andaluz, con la categoría de monumento, el conjunto Dolménico de Valencina de la Concepción y Castilleja de Guzmán, sito en los términos municipales de Valencina de la Concepción y Castilleja de Guzmán (Sevilla). BOJA núm. 30 de 13.02.2003.

4 Texto completo en www.adta.es; y noticia publicada en PH Boletín del Instituto Andaluz del Patrimonio Histórico, n 60, noviembre 2006, pp. 4-17. 